\section{Serial lung function studies in cystic fibrosis in the first 5 years of life}

In cystic fibrosis (CF) plugging of small airways results in airways obstruction and pulmonary hyperinflation, giving rise eventually to damage to lung architecture. It is probable that the earliest lesion is in the small airways, since abnormalities of gas exchange may be detected before abnormality in tests of large airway function (Lamarre et al., 1972). It has been assumed that the effects of the disease only develop postnatally and therefore it is important to determine whether the lungs are functionally normal in early infancy. Phelan et al.(1969) measured lung volume and pulmonary air flow resistance in 9 infants without clinical evidence of pulmonary involvement and found in 3 infants an increase in lung volume, and in 4 infants an increase in resistance. These infants were followed with physiological studies until 6 months of age, and Phelan et al. (1969) showed improvement with treatment.

The relationship of lung function in early infancy to subsequent progress is of particular importance with regard to ultimate prognosis and therapy. In the present study, a small group of infants with CF were studied in the first few months of life using a whole body plethysmograph (Howlett, 1972) and 5 of these infants were restudied in their fifth year using a sensitive radioisotope lung function technique (Ronchetti et al., 1975). The results are presented in relation to the clinical status of the children at the time of each study.

\section{Subjects and methods}

The patients were either sibs of known patients, or presented with meconium ileus. The diagnosis of $\mathrm{CF}$ was confirmed by finding a raised sweat sodium. The study was in two parts.

Part 1. In 1970-1971, 8 infants were studied in the first 7 months of life at Brompton Hospital. 6 of the 8 had presented with meconium ileus and two were sibs of known patients. Clinical details are given in Table 1. Thoracic gas volume (TGV) was measured in a whole body plethysmograph by the occlusion method (DuBois et al., 1956), dynamic compliance (C dyn) and pulmonary resistance ( $R p)$ were measured using an oesophageal balloon with tidal flow and volume being recorded at the mouth. The infants were studied in the supine position and the results compared with data obtained from 24 healthy infants of similar age studied in our laboratory.
Part II. In 1976, 5 of the 8 patients were available for restudy. The clinical course between studies is given in Table 1. Radioisotopic lung function tests were performed at Hammersmith Hospital by the method described previously (Ronchetti et al., 1975). Briefly, the patient lay supine over a gamma camera and a small quantity of radioactive nitrogen $\left({ }^{13} \mathrm{~N}\right)$ was given as a bolus into the inspired air stream. Information on ventilation was derived from the computer curves of the washout of the radioactivity. A bolus of ${ }^{13} \mathrm{~N}$ dissolved in saline was also given intravenously and because of its insolubility, left the pulmonary capillary blood for the alveolar gas and was removed by respiration. A measure of ventilation-perfusion balance was obtained from the washout curve after the intravenous injection. The results from this study were compared with the results from 20 healthy lung zones in 10 children with localised pulmonary disease (Winlove et al., 1978). All results are expressed as percentages of the expected value for the individual child, using normal data from our laboratories.

\section{Results}

The ages and physiological data of the children at the time of the initial and subsequent follow-up are shown in Table 2. At the time of the initial study, the heights and weights ranged from below the 3rd to the 97th centile and all the weights were appropriate for the heights. When the children were restudied, 3 of the 5 had increased their height centile and 2 of these 3 had increased their weight centile. 2 of the 3 children not retested showed a similar pattern of growth but the third had a falling off of both height and weight (Case 7).

Respiratory symptoms varied within the group at initial testing: 3 had had no respiratory smyptoms (Cases 3, 4, 8); 3 had minimal symptoms consisting of occasional cough (Cases 1, 2, 5); and 2 had marked respiratory symptoms which had started in the postoperative period (Cases 6,7 ). 2 of the 3 patients not retested remain free of respiratory symptoms and have clear chest radiographs (Cases 1,8); the third patient is severely disabled and has a poor prognosis (Case 7). He had early onset of respiratory symptoms in the postoperative period.

The results of the lung function tests are given in Table 2, which should be studied together with Table 1. The 3 infants who were asymptomatic initially had lung mechanics in infancy within normal limits and the 3 mildly affected infants showed airways obstruction (low specific conductance), 1 having an associated low compliance. The 2 severely affected infants had abnormal lung function with 
Table 1 Clinical details of the 8 patients

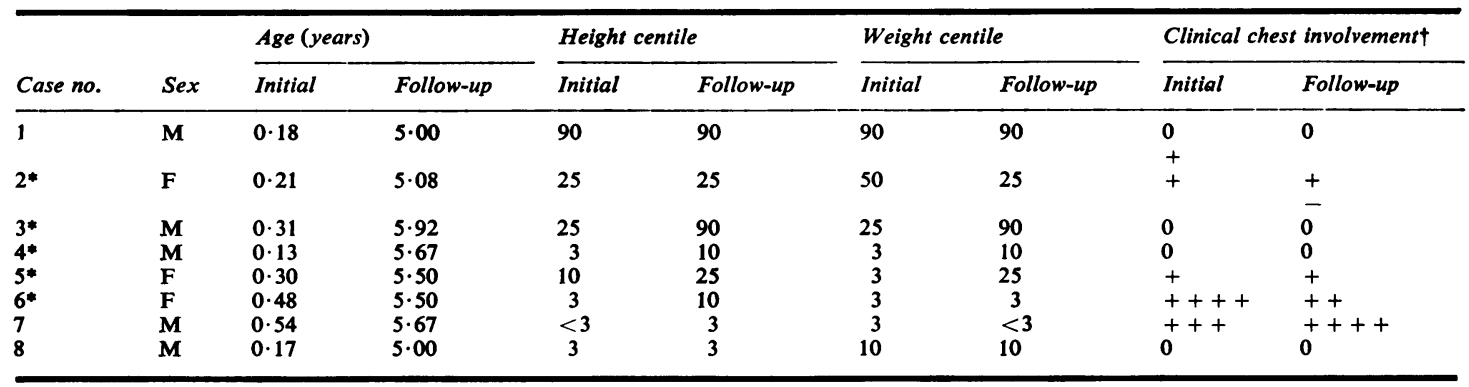

- Patients retested. $+0=$ no cough $;+=$ occasional cough $;++=$ moderate respiratory symptoms $;+++=$ severe respiratory symptoms.

Table 2 Lung function results expressed as per cent normal

\begin{tabular}{|c|c|c|c|c|c|}
\hline \multirow[b]{2}{*}{ Case no. } & \multicolumn{3}{|c|}{ Lung mechanics in infancy } & \multicolumn{2}{|c|}{ Regional lung function aged 5} \\
\hline & Thoracic gas volume & Specific compliance & Specific conductance & Ventilation washout & Perfusion washout \\
\hline 1 & 105 & 86 & 44 & & \\
\hline 2 & 100 & 104 & 49 & 74 & 53 \\
\hline 3 & 100 & 103 & 75 & 78 & 62 \\
\hline 4 & 95 & 102 & 110 & 55 & 89 \\
\hline 5 & 101 & 99 & 48 & 78 & 57 \\
\hline 6 & 145 & 77 & 47 & 56 & 37 \\
\hline 7 & 125 & 85 & 65 & & \\
\hline & 101 & 98 & 140 & & \\
\hline $\begin{array}{l}2 \text { SDs away from normal } \\
\text { mean }\end{array}$ & $\geqslant 110$ & $\leqslant 86$ & $\leqslant 56$ & $\leqslant 61$ & $<74$ \\
\hline
\end{tabular}

Specific compliance $=$ Compliance/Thoracic Gas Volume.

Specific conductance $=($ Conductance/Thoracic Gas Volume $)=(1 /$ Resistance $\times$ Thoracic Gas Volume $)$.

hyperinflation, airway obstruction, and low compliance.

At follow-up 5 years later, 2 of the 3 asymptomatic infants were retested (Cases 3,4$)$ and showed distinct abnormalities despite still being asymptomatic. 2 of the 3 who initially had mild symptoms were retested (Cases 2, 5) and both showed abnormal function despite their modest clinical symptoms. 1 of the 2 severely affected infants was retested (Case 6) and showed severely disordered regional lung function although free of productive cough and gaining weight appropriate for height.

\section{Discussion}

The results of the study of lung mechanics in this small group of infants with CF were similar to those obtained by Phelan et al. (1969). Airways obstruction and hyperinflation was evident in the more severely affected children and functional disturbance was detected even in children with minimal symptoms (Cases 2, 4, 5). None of our asymptomatic infants had any abnormality, but 3 out of 5 infants considered asymptomatic in the study of Phelan et al. (1969) had thoracic gas volumes well above our upper limit of normal $(39.1 \mathrm{ml} / \mathrm{kg})$, which is in fact even a little higher than their own upper limit of normal.

Our study suggests that the lungs of infants with CF are physiologically normal at birth but disturbance of function arises even in the absence of clinical symptoms. In general terms, there was agreement between the clinical status of the child and both the lung mechanics in infancy and the radioisotopic lung function tests at 5 years, though it is not possible to quantitate this owing to the small numbers. There was a tendency for specific conductance to fall with mild symptoms, a low compliance and hyperinflation only occurring in the more severe cases. The ventilation and perfusion washout curves were abnormal in virtually every case, though again, the magnitude of the reduction in rate of washout after perfusion tended to reflect the clinical state at the time.

It is perhaps disappointing that there was no physiological improvement in any patient, especially when all but one were maintaining their height and weight centile and were without persistent productive cough. It appears that physiological damage may be subclinical and that once the lungs are physiologically disordered, there is persistence or progression of the abnormality. 


\section{Summary}

Lung mechanics were studied in 8 infants with cystic fibrosis at 6 months of life and radiosotopic lung function was measured in 5 of them at 5 years of age. The children who were initially asymptomatic had normal lung mechanics in infancy but the 2 restudied later had abnormal radioisotopic lung function. The symptomatic children showed abnormalities in infancy and more marked changes later. It is concluded that the lungs in cystic fibrosis are probably normal initially and that damage occurs later even in the absence of symptoms.

\section{References}

DuBois, A. B., Botelho, S. Y., Bedell, G. N., Marshall, R., and Comroe, J. H., Jr. (1956). A rapid plethysmographic method for measuring thoracic gas volume: a comparison with a nitrogen washout method for measuring functional residual capacity in normal subjects. Journal of Clinical Investigation, 35, 322-326.

Howlett, G. (1972). Lung mechanics in normal infants and infants with congenital heart disease. Archives of Disease in Childhood, 47, 707-715.

Lamarre, A., Reilly, B. J., Bryan, A. C., and Levison, H. (1972). Early detection of pulmonary function abnormalities in cystic fibrosis. Pediatrics, 50, 291-298.

Phelan, P. D., Gracey, M., Williams, H. E., and Anderson, C. M. (1969). Ventilatory function in infants with cystic fibrosis. Archives of Disease in Childhood, 44, 393-400.

Ronchetti, R., Stocks, J., Freedman, N., Glass, H., and Godfrey, S. (1975). The clinical application of regional lung function studies in infants and small children using ${ }^{13} \mathrm{~N}$. Archives of Disease in Childhood, 50, 595-603.

Winlove, P., Freedman, N., Fitzpatrick, M. L., and Godfrey, S. (1978). The quantitation of regional lung function in infants and children using radioactive nitrogen $\left({ }^{13} \mathrm{~N}\right)$. (Submitted for publication).

\section{S. Godfrey, M. Mearns, and G. Howlett}

Department of Paediatrics and Neonatal Medicine, Hammersmith Hospital; Queen Elizabeth Hospital for Children; and Department of Paediatrics, Brompton Hospital, London.

Correspondence to Dr M. Mearns, Queen Elizabeth Hospital for Children, Hackney Road, London E2 8PS.

\section{Hyponatraemia in children with febrile convulsions}

In a recent study of investigations routinely performed in children admitted to hospital with a febrile convulsion, we found that mild hyponatraemia was common (Rutter and Smales, 1977). In 163 children, the mean sodium was $135 \pm 4 \mathrm{mmol} / 1( \pm \mathrm{SD})$ with a range of $125-145 \mathrm{mmol} / 1.31 \%$ had plasma $\mathrm{Na}$ levels of $132 \mathrm{mmol} / \mathrm{l}$ or less. To investigate this further, we started a prospective study comparing the plasma $\mathrm{Na}$ and osmolality with the urine osmolality, looking for evidence of inappropriate secretion of antidiuretic hormone (ADH).

\section{Method}

Urea, electrolytes, sugar, and osmolality were measured on venous blood taken on admission from randomly selected children admitted to Nottingham Children's Hospital with a diagnosis of a febrile convulsion. Osmolality was measured on the first specimen of urine passed after admission. The time of the urine collection was recorded. Where the time of the specimen was uncertain or more than 6 hours after admission, the child was excluded from the study.

\section{Results}

Twenty-three children were studied, one child being admitted on two separate occasions. Their ages ranged from 8 months to 5 years. Plasma Na, osmolality, and urine osmolality are shown in the Fig. The mean $\mathrm{Na}$ was $133 \pm 3 \mathrm{mmol} / \mathrm{l}$ and mild hyponatraemia was present in 8 cases $(132 \mathrm{mmol} / 1$ or less). Details of these hyponatraemic children are shown in

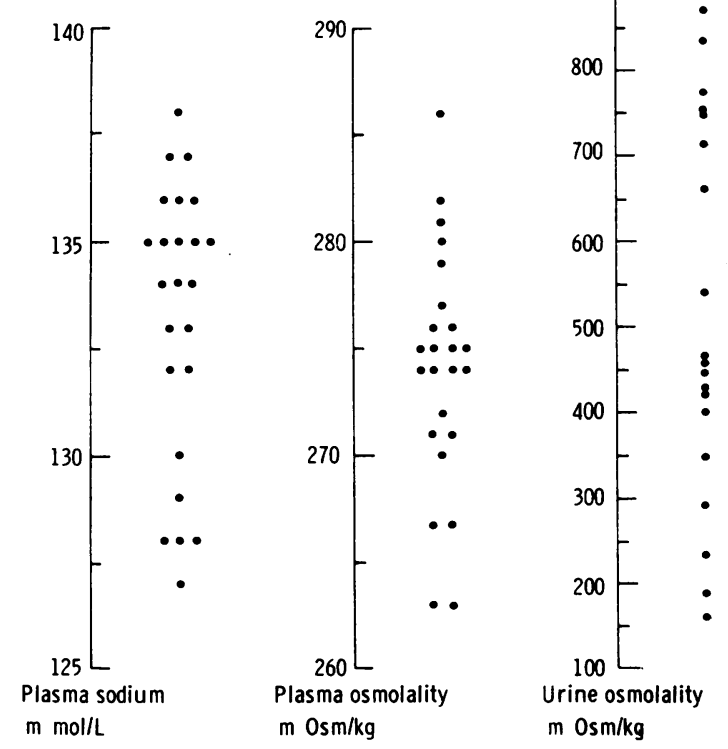

Fig. Plasma sodium, plasma and urine osmolalities of 23 children admitted after a febrile convulsion. 